6-13-2013

\title{
Regrouping: Organized Activity Involvement and Social Adjustment Across the Transition to High School
}

Amy M. Bohnert

Loyola University Chicago, abohner@luc.edu

Julie Wargo Aikins

Nicole T. Arola

Loyola University Chicago

Follow this and additional works at: https://ecommons.luc.edu/psychology_facpubs

Part of the Psychology Commons

\section{Recommended Citation}

Bohnert, A. M., Wargo Aikins, J., \& Arola, N. T. (2013). Regrouping: Organized activity involvement and social adjustment across the transition to high school. In J. A. Fredricks \& S. D. Simpkins (Eds.), Organized Out-of-School Activities: Settings for Peer Relationships. New Directions for Child and Adolescent Development, 140, 57-75.

This Article is brought to you for free and open access by the Faculty Publications and Other Works by Department at Loyola eCommons. It has been accepted for inclusion in Psychology: Faculty Publications and Other Works by an authorized administrator of Loyola eCommons. For more information, please contact ecommons@luc.edu. cc) (i) $\ominus$

This work is licensed under a Creative Commons Attribution-Noncommercial-No Derivative Works 3.0 License. (c) Wiley Periodicals, 2013. 
Bohnert, A. M., Wargo Aikins, J., \& Arola, N. T. (2013). Regrouping: Organized activity involvement and social adjustment across the transition to high school. In J. A. Fredricks \& S. D. Simpkins (Eds.), Organized Out-of-School Activities: Settings for Peer Relationships. New Directions for Child and Adolescent Development, 140, 57-75.

\title{
Regrouping: Organized Activity Involvement and Social Adjustment Across the Transition to High School
}

\author{
Amy M. Bohnert, Julie Wargo Aikins, Nicole T. Arola
}

\begin{abstract}
Although organized activities (OAs) have been established as important contexts of development, limited work has examined the role of OAs across the high school transition in buffering adolescents' social adjustment by providing opportunities for visibility and peer affiliation. The transition to high school is characterized by numerous changes and OAs may provide an important setting for establishing and maintaining peer relationships during this tumultuous time. This study included 151 8th grade U.S. students (58\% male) who were assessed across the transition to high school (spring of 8th and 9th grade). Continuous involvement in academic activities across the transition and becoming involved (i.e., initiation) in community/service activities following the transition was associated with fewer depressive symptoms in the spring of 9th grade. Continuous involvement in sports and initiation of academic activities was associated with having more friendships. In addition, links between OAs and loneliness were only evident among females. There appear to be significant social benefits for OA involvement. (C) 2013 Wiley Periodicals, Inc.
\end{abstract}




\section{Introduction}

$\mathrm{D}$ elineating processes of continuity and change is a fundamental issue for the field of developmental psychology. Transitions from one developmental stage to another (e.g., middle childhood to adolescence) or one context to another (e.g., middle school to high school) present unique opportunities to examine these processes, and have long been thought of as providing opportunities for growth as well as potential risks to adaptation (Bronfenbrenner, 1979; Dohrenwend \& Dohrenwend, 1974; Schulenberg, Sameroff, \& Cicchetti, 2004). Developmental psychology has focused primarily on how adults and adult-led institutions, such as schools, may influence a youth's social adjustment across transitions (Zimmer-Gemback \& Kindermann, 2010). Of considerable interest though is how self-selected contexts, such as organized activities (OA), might contribute to adjustment across a transition. Although organized activities are largely recognized as an important context of development, virtually nothing is known about how staying involved in activities across a transition (i.e., continuity) may influence social adjustment. Furthermore, the transition to high school (i.e., moving from middle to high school) may be a particularly important time to examine social adjustment given the difficulties that can arise at this point in development.

The transition to high school typically involves not only moving to schools that are larger in size with increased enrollments, but often also includes lower levels of support and increased expectations for autonomy and responsibility (Cantin \& Boivin, 2004; Eccles, 2004). For some adolescents, this transition is marked by drops in self-esteem as well as increases in depression and psychological distress (Barber \& Olsen, 2004; Chung, Elias, \& Schneider, 1998; Wigfield, Eccles, Mac Iver, Reuman, \& Midgley, 1991). The transition can also lead to the disruption of already established peer groups and networks, undermining group acceptance and friendships for some adolescents (Bukowski \& Newcomb, 1984; Cantin \& Boivin, 2004; Hardy, Bukowski, \& Sippola, 2002; Hirsch \& Dubois, 1992). These disruptions come at a critical point in development when friendships and social acceptance are particularly salient (Berndt, 1982; O'Brien \& Bierman, 1988). In addition, during this point in development, the amount of time and effort that is spent engaged in peer-related activities increases (Ellis, Rogoff, \& Cromer, 1981), and the broad influence that peer relationships have on adolescents' functioning across social domains is heightened (Berndt, 1989; Parker \& Asher, 1987).

Despite researchers' speculations regarding the importance of peer relationships during this time and the potential social challenges and opportunities inherent in the transitioning to high school, only one study has examined social adjustment across this transition. Cillessen and Mayeux (2007) found that being well-liked and popular with peers prior to the high school transition was predictive of higher self-perceptions of 
social adjustment following the transition. Although this study suggested that pre-transition social success may lead to better post-transition social adjustment, the mechanism by which social adjustment was supported was not examined. The current study was designed to address several questions regarding the relevance of organized activities for social adjustment following the transition to high school. First, we examined whether adolescents' continuous involvement in organized activities (OAs) across the transition to high school or initiation of involvement in new OAs following the transition might promote better social adjustment. Next, we considered whether different patterns and types of organized activity involvement were more important for boys' social adjustment as compared to girls. Finally, we tested whether peer status serves as the mechanism linking OAs to two forms of adjustment (i.e., depressive symptoms and loneliness) across the transition (see Figure 1). Only a few studies to date have considered whether peers mediate associations between OAs and development (see Eccles, Barber, Stone, \& Hunt, 2003; Fredricks \& Eccles, 2005), and these primarily focus on the nature of one's peer group (i.e., how prosocial they are) rather than one's peer status (i.e., how popular and well-liked an individual is).

Organized activities (OAs) provide a context in which adolescents can interact with like-minded peers, which may prove beneficial to their social adjustment in numerous ways. Given the challenges faced when making the transition to high school, maintaining involvement in an activity that an adolescent already identifies with and is connected to peers through (i.e., continuity) may facilitate better adjustment. Staying involved may represent a source of constancy and stability during a period of significant change. Involvement in OAs may also provide adolescents with a smaller setting within the larger school context in which to feel socially accepted and satisfied at a particular point in development in

\section{Figure 1. Peer Status as Mediators Between Organized Activity Involvement and Depressive Symptoms and Loneliness}

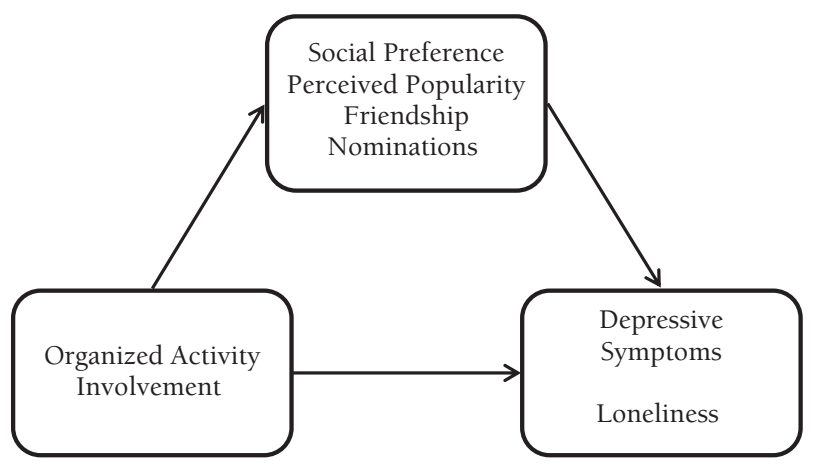


which these feelings of acceptance may be especially salient (e.g., Berndt, 1982). Indeed, in one study of high school students, greater duration of $\mathrm{OA}$ involvement was associated with lower levels of loneliness among adolescents (Randall \& Bohnert, 2009), while a second study found that the benefits of $\mathrm{OA}$ involvement for social acceptance and depression were evident at moderate but not high levels of involvement (Randall \& Bohnert, 2011).

With the move to a new and usually larger school, adolescents also likely find that continued participation in particular OAs leads to involvement with a familiar as well as a new set of peers, creating a context in which to both maintain old friendships while developing new ones. This premise was supported by recent work by Schaefer, Simpkins, Vest, and Price (2011) who indicated that activity involvement served to both develop and maintain friendships. Notably, adolescents themselves frequently mention friendship acquisition as a benefit of activity participation (Dworkin, Larson, \& Hansen, 2003; Patrick et al., 1999). Moreover, involvement in these activities appears to promote interpersonal skill development (e.g., teamwork and social skills; Hansen, Larson, \& Dworkin, 2003; Patrick et al., 1999) that might further support the growth of friendships over time. Adolescents' indicate that friendships that occur within an activity context are characterized by greater intimacy and fellowship as a result of their mutual participation (Patrick et al., 1999), suggesting that these relationships are stronger and more likely to be maintained over time.

In addition to facilitating friendships, participation in organized activities may promote social status within the school by enhancing adolescents' visibility and peer standing. Teachers rated students as being more popular if they were consistently involved in school-based organized activities during adolescence (Mahoney, Cairns, \& Farmer, 2003). To date, only one study has relied on peer ratings to examine how involvement in OAs affects peer status. Eder and Kinney's (1995) longitudinal study of middle school students found that while popularity was largely stable across middle school, involvement in highly visible activities (e.g., basketball for males and cheerleading for females) contributed to the greatest increases in popularity, while participation in less visible activities (e.g., band) were associated with decreases in popularity. Similarly, participating in certain athletic activities (e.g., football, basketball, wrestling for boys and cheerleading for girls) was associated with increases in social preference (i.e., how well-liked you are) across middle school. These findings suggest that involvement in particular types of organized activities may be associated with increases in peer status across middle school. In addition, these findings highlight that boys and girls appear to value different activities in part because perhaps they recognize that certain types of OAs are more likely to enhance their social reputation and visibility whereas other OAs may not. Other studies have reported differential effects of OA involvement on 
adjustment for boys versus girls (Denault \& Poulin, 2008; Randall \& Bohnert, 2011). In addition, research suggests that girls often reap more social and emotional benefits from activity participation than boys (Fredricks \& Eccles, 2008; Simpkins, Eccles, \& Becnel, 2008). Collectively, these findings suggest the importance of examining whether the associations between $\mathrm{OA}$ involvement and social adjustment may vary based on gender.

To date, only two studies have directly examined the effects of OA involvement on social adjustment prior to and following a transition to a new school context (see Bohnert, Aikins, \& Edidin, 2007; Busseri et al., 2011). In a longitudinal study of the transition to college, Bohnert et al. (2007) found that more intense involvement in activities during the first year of college was associated with better friendship quality, lower ratings of loneliness, and lower social dissatisfaction for those emerging adults with poor social adaptation before college. Busseri et al. (2011) also investigated $\mathrm{OA}$ involvement across the transition to college and found that increases in breadth and intensity of OA involvement from high school to college were associated with higher levels of perceived social support, lower levels of depressive symptoms, and better overall adjustment to college. These findings suggest that maintaining levels of OA involvement may promote better adjustment across the transition to college; however, no study to date has considered whether adolescents' social adjustment is enhanced by staying involved in certain types of activities across a transition to a new school.

In addition to having a direct effect on social adjustment, this study examined a mediational model in which organized activities promote better adjustment by facilitating better peer status (see Figure 1). Friendships may provide a secure relationship base from which to comfortably explore the new environment, and may foster greater competence and security in meeting transition challenges. Previous research has demonstrated that high quality friendships and peer acceptance prior to the junior high school transition were predictive of more positive self-esteem, social selfperceptions, school integration, and overall adjustment following the transition (Berndt, Hawkins, \& Jian, 1999; Fenzel \& Blyth, 1986; Wargo Aikins, Bierman, \& Parker, 2005). In addition, being well-liked and popular with peers prior to the high school transition also appears to facilitate social adjustment across the high school transition (Cillessen \& Mayeux, 2007). As such, we hypothesize that certain aspects of peer status (social preference, perceived popularity, and friendship nominations) mediate the relations between OAs and social adjustment including fewer depressive symptoms and less loneliness for adolescents across the transition.

Assessing Activity Involvement. Maintaining involvement in a certain type of activity (e.g., swimming, band) requires both persistence and dedication, and may be more important to consider than whether an adolescent stays involved in any activity across a transition (Bohnert, 
Fredricks, \& Randall, 2010). In addition, staying involved in the same type of activities across a transition is likely to build on existing strengths and help solidify both one's social identity and existing peer relationships (e.g., Eccles \& Barber, 1999). Studies examining the benefits of ongoing $\mathrm{OA}$ involvement have reported that more years of involvement in school clubs, performing arts, and student government was associated with better academic functioning, better psychological adjustment, and lower rates of substance use (Fauth, Roth, \& Brooks-Gunn, 2007; Fredricks \& Eccles, 2006). More years spent in sports was associated with better academic functioning and psychological adjustment, but also higher rates of alcohol use and delinquency (Broh, 2002; Fauth et al., 2007; Fredricks \& Eccles, 2006).

One of the central premises of this chapter is that patterns of continuity (and discontinuity) in adolescents' involvement in particular types of OAs across the high school transition may be important to examine for a number of reasons. Adolescents may be buffered from some of the negative consequences associated with the disruptions that characterize the transition to high school by continuing their involvement in familiar activities in which they may have a pre-existing or easily accessible peer system. These OAs also may provide adolescents with opportunities for peer affiliations and visibility that may advance their peer status within the larger peer group. Given the challenges faced when making the transition to high school, it is hypothesized that maintaining involvement in an activity that an adolescent already identifies with and is connected to peers through (i.e., continuity) may facilitate better social outcomes than simply getting involved in high school for the first time (i.e., initiation).

The Current Study. This longitudinal study used questionnaires and well-validated peer nomination/sociometric procedures to examine: (1) relations between patterns of continuity in activity involvement in five widely recognized types of organized activities (i.e., religious, academic, performance/arts, sports, and community/service) and social adjustment across the transition to high school, (2) whether these relations are moderated by adolescents' gender, and (3) whether peer status variables mediate the relation between patterns of activity involvement and depressive symptoms and loneliness.

\section{Method}

Participants were 151 students ( $58 \%$ male; $n=88$ ) who were part of a larger longitudinal study. The original sample consisted of 279 8th grade students aged 12-14 at the beginning of the study, who attended three suburban middle schools in the Northeastern United States. These schools ranged in per capita income from $\$ 35,087$ to $\$ 77,794(M=\$ 58,465, S D$ $=\$ 16,036)$. Of these 279 students, $54 \%(n=128)$ did not have complete activity data for 8th and 9th grade and therefore were not included in 
these analyses. The analytic sample was similar to the original sample on all demographic variables with the exception of social preference and friendship nominations which were higher at $\mathrm{Tl}$ (statistics are available from the first author). In addition, peer nomination data was only available on a smaller subsample of the analytic sample $(n=77)$, and there were no group differences between this smaller subsample and the overall analytic sample. Participants reported information at Time 1 (spring of 8th grade), and approximately 11 months later (Time 2: spring of 9th grade).

\section{Measures}

Multi-reporter and methods of measurement were used to obtain a broader view of youth functioning and to avoid associations emerging as a result of single method variance.

Peer Status. Peer nominations were used to examine three distinct peer status variables: social preference, perceived popularity, and friendship nominations. Participating students were provided with an alphabetized list with names and codes for all grade mates in their school, and were asked to select an unlimited number of peers who they "liked most" and "liked least" (social preference), who were "most popular" and "least popular" (perceived popularity), and whom they considered friends (friendship nominations). For each question, nominations received were counted and standardized within the reference group (the entire grade level of each school). Continuous measures of perceived popularity and social preference were computed by subtracting the standardized number of liked least or least popular votes received from the standardized number of liked most or most popular votes. The difference scores obtained were standardized again to a mean of 0 and standard deviation of 1 in the reference group. Friendship nominations were summed and standardized within the grade.

Depressive Symptoms. Participants completed the Children's Depression Inventory (CDI; Kovacs, 1992) to assess their level of depressive symptoms. The CDI is a widely used 27 -item self-report measure that includes affective, cognitive, motivational, and somatic symptoms of depression. The item assessing suicidal ideation was not used in this study, resulting in a 26-item scale. Mean scores were computed for each student, with higher scores reflecting greater levels of depressive symptoms. Cronbach's alpha for the CDI was .85 .

Loneliness. To assess participant's feelings of loneliness, they completed the Loneliness and Social Dissatisfaction Questionnaire (Asher \& Wheeler, 1985). This scale contains 16 items that assess feelings of loneliness versus satisfaction with current peer relationships and social support. Mean scores of the 16 primary items were computed for each participant, with higher scores reflecting greater feelings of loneliness and social dissatisfaction. Cronbach's alpha for this measure was .77. 
Organized Activity Involvement. At both time points, participants listed all the organized activities they were currently involved in. Each participant received a dummy code $(0 / 1)$ for 8 th and 9 th grade participation in each of five categories of activity involvement (i.e., religious, academic, performance/arts, sports, and community/service). Participants who participated in at least one activity within each category at any point received a score of 1 for that category.

Next, we coded patterns of involvement for each of the five categories across the transition to high school. Participants who did not participate in a given category at both times points (i.e., 8 th grade $=0$, 9th grade $=$ 0 ) were coded as no involvement. Those individuals who participated in a category prior to high school, but who no longer participated in this category in high school (i.e., 8th grade $=1$, 9th grade $=0$ ) were labeled desistors. Participants who did not participate in a given category prior to high school, but who did participate in this category following the transition to high school were labeled initiators (i.e., 8 th grade $=0$, 9th grade $=1$ ). Finally, participants who participated in a given category at both $\mathrm{Tl}$ and T2 (i.e., 8th grade $=1$, 9th grade $=1$ ) were labeled as the continuously involved group for that specific category of organized activity involvement.

There was significant variability in the number of participants falling into each group of involvement (i.e., no involvement, desistors, initiators, and continuously involved) based on activity category, with very low cell sizes for certain groupings. Given this, we were unable to use the fourlevel coded conceptualization of involvement in the categories beyond providing descriptive statistics. In addition, given our interest in examining the social adjustment outcomes associated with two particular patterns of involvement (i.e., continuously involved and initiators), we created two dummy variables for each of these patterns to represent whether a participant was an initiator or not and whether they were continuously involved or not across the transition to high school.

\section{Results}

To examine associations between patterns of activity involvement and social adjustment across the transition to high school and whether these relations were moderated by gender, multiple regression equations were estimated (i.e., Baron \& Kenny, 1986; Holmbeck, 2002). Adolescents' 8th grade adjustment on the corresponding outcome variable and gender were entered on the first step. The dummy codes for initiators and continuously involved for each specific category were entered on step 2, followed by the initiator by gender and continuously involved by gender interaction terms on step 3. Analyses were run for each of the five types of activity involvement, and for each of the five social adjustment variables. When significant interactions were detected, post-hoc probing via tests of simple slopes was conducted. In addition, mediation models were tested using 
bootstrapping to determine whether peer status in the spring of 9th grade mediated the association between patterns of OA involvement in the spring of 8th grade and depressive symptoms and loneliness assessed in the spring of 9th grade (Hayes, 2009).

Descriptive Statistics. As shown in Table 1, social adjustment remained relatively stable across the transition to high school. Paired samples t-tests revealed only two significant differences between 8th and 9th grade levels of social adjustment, with significant decreases in loneliness, $t(149)=16.02, p<.001$, and increases in perceived popularity, $t(76)=$ $-2.80, p=.007$. Females and males had similar levels of social adjustment, but a greater percentage of females were continuously involved in performance activities, $\chi^{2}(1, N=151)=4.06, p=.04$. The majority of participants were continuously involved in at least one activity across the transition to high school (95\%). As shown in Figure 2, the highest levels of continuity were found for sports and performance activities. For sports only though, the vast majority of participants were continuously involved across the transition to high school.

Relations Between Patterns of $\mathrm{OA}$ Involvement and Social Adjustment. Adolescents who were continuously involved in academic activities from 8th to 9th grade as well as those who initiated involvement in community/service activities in 9th grade reported lower levels of depressive symptoms $(\beta=-.13, p=.037 ; \beta=-.20, p=.002$, respectively). Adolescents who maintained involvement in sports from 8th to

Figure 2. Patterns of Activity Involvement Across the Transition to High School

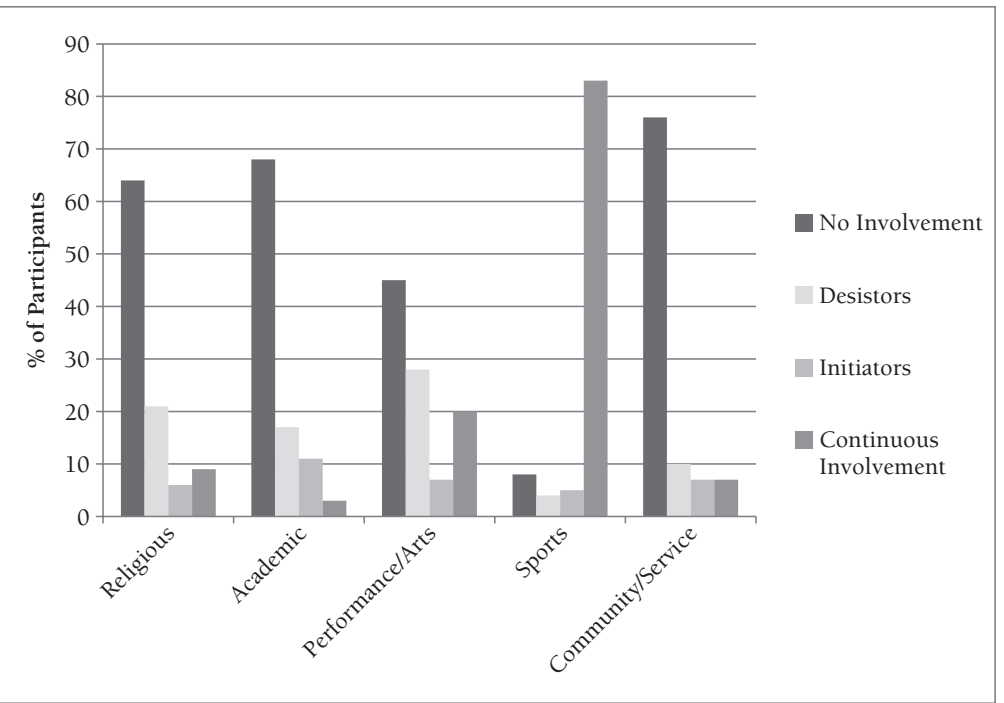




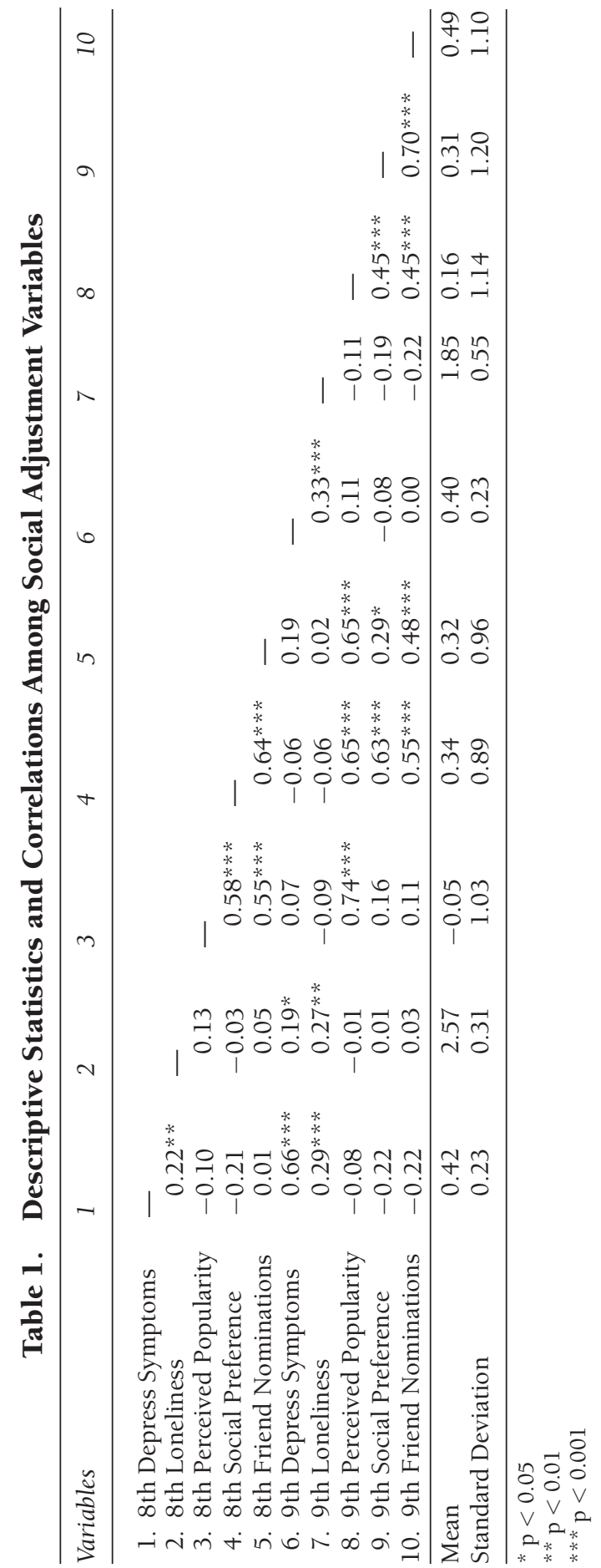


9th grade as well those who got involved in academic activities in 9th grade had more peers nominate them as friends $(\beta=.27, p=.040 ; \beta=$ $.26, p=.015$, respectively). No other significant main effects were found.

Gender as a Moderator of Relations Between Patterns of OA Involvement and Social Adjustment. In two instances, the relations between OA involvement and adjustment varied by gender. Continuity in academic activities across the transition to high school was significantly related to more loneliness for females $(\beta=.34, p=.007)$, but was insignificant for males $(\beta=-.09, p=.391)$. This suggests that adolescent females who are continuously involved in academic activities from 8th to 9th grade experience elevated levels of loneliness following the transition to high school. In contrast, continuity in sports was significantly associated with lower levels of loneliness among females $(\beta=-.43, p=.001)$, but not males $(\beta=-.17, p=.093)$, indicating that adolescent females who are continuously involved in sports experience lower ratings of loneliness in 9th grade. Gender was not a significant moderator in any additional analyses.

Peer Status as a Mediator of Relations Between OA Involvement and Social Adjustment. None of the models examining peer status as a mediator of the relation between patterns of $\mathrm{OA}$ involvement across the transition to high school and social adjustment were significant. This suggests that enhanced peer status does not explain the association between patterns of $\mathrm{OA}$ involvement across the transition to high school and depressive symptoms and loneliness.

\section{Discussion}

The present investigation provided new insights into the role of organized activities in facilitating social adjustment across developmental transitions. The transition to high school is thought to pose risks to adolescents' social and emotional adjustment given the high degree of change and the lack of support (e.g., Cantin \& Boivin, 2004; Eccles, 2004). In fact, this study suggests that adolescents who both initiate and stay involved in organized activities across the transition to high school may experience social and emotional benefits.

Continuous involvement in sports activities and the initiation of academic activities were both associated with having more friends following the high school transition. Given the contextual, academic, and social disruptions associated with the high school transition, it follows that adolescents' ability to remain engaged in activities over the course of the transition may allow them to create for themselves a sense of order within a system that is in disarray. Involvement in a sports activity that involves a sense of camaraderie and the achievement of a goal through teamwork may promote positive coping and facilitate peer affiliation 
(Eccles \& Barber, 1999). Indeed, research to date has suggested that sports participation through the high school years is predictive of greater feelings of school engagement, better school performance, and increased selfesteem (Broh, 2002; Fredricks \& Eccles, 2006) that in turn may lay the groundwork for friendship formation.

Findings from this study suggested that adolescents were more likely to initiate involvement in academic activities in high school than any other kind of activity, perhaps suggesting the availability of this kind of activity following the transition to high school. Some adolescents may find a niche in academic activities that was unavailable during their middle school years. Moreover, this study suggested that the initiation of academic activities contributed to higher rates of friendship nominations. As such, it seems plausible that involvement in academically based activities might provide a context for friendship formation among a group of youth who may not have been involved in sports activities or other kinds of activities that predominated the middle school context. In this sense, the provision of a more diverse set of well-defined and elaborated activities may create new opportunities for friendship formation among academically inclined adolescents.

In contrast to the positive consequences associated with initiating participation in academic activities during high school, continued involvement in academic activities was associated with higher levels of loneliness for adolescent girls. Perhaps girls who get involved at this time and maintain their participation in academic activities through high school may be a more extreme or marginalized group given the limited availability of academic activities during middle school. Eder and Kinney (1995) suggest that involvement in low status activities is associated with decreases in popularity. Thus, it is possible that getting involved in an activity when the visibility is very low and maintaining that involvement in an activity leads to heightened social isolation particularly for girls who may be more susceptible to the negative effects of being in a more marginalized peer group at this point in development.

Results of this study also indicated that adolescent girls who continuously participated in sports activities experienced lower levels of loneliness and social dissatisfaction across the transition to high school. Female athletes, more so than their male peers, have been found to focus on the socio-emotional aspects of participation, placing greater emphasis on the related benefits of participation such as camaraderie and identification with team members (Weiss \& Frazer, 1995). Given girls' greater needs for relationships during adolescence (Cyranowski, Frank, Young, \& Shear, 2000), they may be more aware of and sensitive to the interpersonal interactions and implications of their activity involvement. Indeed, prior research suggests that girls often reap more social and emotional benefits from activity participation than boys (Fredricks \& Eccles, 2008; Simpkins et al., 2008). Additionally, participation in activities such as sports 
frequently brings about high visibility within the peer group (Duda \& Ntoumanis, 2005; Eder \& Kinney, 1995) that may dampen feelings of loneliness and promote more satisfaction with peer experiences as well.

The higher rates of friendship nominations associated with certain types and patterns of activity involvement may also be reflective of homophily, which might be particularly salient during this time period (e.g., Goodwin, Mrug, Borch, \& Cillessen, 2012). The selection of partners who engage in similar behaviors or share similar attitudes is a particularly robust finding and points to the basic social-emotional satisfaction and interpersonal ease that emerges from relationship choices based on similarity (see review by McPherson, Smith-Lovin, \& Cook, 2001). In this manner, activity involvement allows for engagement with peers who adolescents believe are likely to enjoy the same things, be alike across a number of dimensions, and hold similar values. At a base level, by choosing an activity to be involved in, adolescents know that they both enjoy that activity; however, activity involvement may also be a proxy for other characteristics that the activity demands, such as determination, competitiveness, or intelligence, that therefore may serve as common characteristics that are the basis for friendship selection. Observable similarities, such as activity involvement, may be particularly salient following the transition when adolescents are trying to find their social place within the new environment and may use evident characteristics such as activity involvement as indicators of broader individual characteristics. Adolescents may use activity involvement as a means for friendship selection by either continuing those activities that they have enjoyed in the past or by initiating involvement in new activities. Although selection effects were not directly measured in this study, future research should examine whether other similarities exist among youth who engage in these activities and serve as the basis for friendship formation and maintenance that are derived from adolescents' involvement. One question for future inquiry is why some types of activities seem to promote friendships while others may do so, but to a lesser degree.

Although peer relationships take on increasing importance during adolescence, parents continue to play an important role in adolescents' lives. As such, the influence of continuous activity participation may also in part be explained by parent involvement. While most parents provide their children with heightened levels of school-related autonomy following the transition to high school (Falbo, Lein, \& Amador, 2001), parents of successful high school students have often taken an active role during earlier school years in engaging their children in activities that might be continued into the high school period (e.g. band, sports teams, academic clubs; Falbo et al., 2001). By paying for lessons, supporting their practice, and even pressuring their children to choose one type of activity versus another parents may serve early on as "social architects," shaping the kinds of peers their children befriend and the kinds of experiences they 
are likely to have by influencing the kinds of organized activities they engage in. These parents have also been found to play more active roles in their children's activities even at the high school level through activities such as fund raising or chaperoning. In this manner, parents may get to know school administrators and teachers who in turn may provide parents with information about their children and may observe their children engaging with their peers; all resulting in heightened levels of parental monitoring which may contribute to lower levels of adjustment difficulties as well as greater social facilitation.

By examining patterns of continuity and initiation in $\mathrm{OA}$ involvement in particular types of activities, this research builds on previous studies that have only considered changes in overall levels of intensity or breadth (see Bohnert et al., 2007; Busseri et al., 2011). Involvement in specific types of activities may be important to consider, given the unique benefits of particular activities (e.g., Fredricks \& Eccles, 2006) as well as the potential for ongoing involvement in the same activities to facilitate one's social identity and existing peer relationships (e.g., Eccles \& Barber, 1999). Findings from this study suggest that patterns of involvement across the high school transition varied by activity type. Adolescents were most likely to maintain their involvement in sports followed by performance/arts activities across the transition. A high degree of continuity in these two types of activities is not surprising given the availability of these types of activities during middle school as well as the skilled nature of these activities that often require children to make a significant time commitment to developing their skills and talents prior to high school. Interestingly though, it appears that on average, adolescents who maintained their involvement in one type of activity appeared to be more likely to do so in another activity as well. Perhaps those adolescents who value engagement in OAs and see the benefits that these may provide both prior to and across the transition are more likely to remain active in multiple OAs than their less involved peers.

In contrast to our predictions, sociometric/peer ratings of liking and popularity were not significantly associated with patterns of organized activity involvement. This finding may be the function of the small sample size. In addition, the stability in adolescents' popularity over time left little variability to be predicted. Indeed, continuity in sports was associated with higher levels of perceived popularity when 8th grade popularity was not controlled. Failure to find any significant associations between OA and peer likability, however, was unexpected. To date, research has suggested that the visibility gained by participating in athletic activities and the socially deemed importance and selectivity of these groups may be important predictors of popularity. Yet, the value that certain groups hold within varying school settings may not be consistent across all schools and as such may not carry the same advantages. It is possible that participation in only certain sports rather than in sports more generally convey certain 
social advantages within the larger peer group, contributing to heightened levels of perceived popularity (Eder \& Kinney, 1995). In addition, involvement in other types of activities such as leadership activities may be more valued within the schools included in this study and as such the social advantages of participation were not captured by our analyses. Future work may benefit not only from examining adolescents participation in various kinds of activities, but also by assessing the meaning or social value of these activities within the social context as a means for better understanding the social capital they may convey.

Mediation models that examined whether activities promote better social adjustment through enhancing peer status were also not significant. These findings stand in contrast to prior work that has found partial support for the notion that peers mediate associations between OAs and development (see Eccles et al., 2003; Fredricks \& Eccles, 2005). In these prior studies, the peer variables included in mediation models captured the prosocial nature of ones' peers rather than how one is regarded by peers more globally, which may account for the contradictory findings. Weak associations between popularity and OAs may have also contributed to the lack of mediation findings. However, the fact that maintaining involvement in sports was positively linked to the number of friendship nominations received in the current study as well as recent findings suggesting that OAs serve to both maintain friendships and promote new friendships (see Schaefer et al., 2011), the influence of particular types of OAs on specific dimensions of friendships, such as a quality, is an important area of future inquiry.

Although this study presented a new way of capturing organized activity involvement across transitions and had a number of promising findings related to social adjustment in high school, a number of limitations must be considered. First, the size of the sample was relatively small which not only may have compromised the generalizability of the results, but also limited our ability to fully examine the four possible patterns of activity involvement across the transition to high school. Second, because a sizeable proportion of participants from the larger study did not have complete data (and thus were not included in this study), the present results may not generalize to all participants from the larger study or to students making the transition high school in other areas. Our sample was not representative of high school students in general, and replication with a representative student sample is required before there can be wider generalizability of our findings. Third, although it was possible to track whether participants were engaged in the same general category (e.g., sports), it was not possible to know whether they stayed involved in the same activity within these broader categories (e.g., swimming). Finally, despite using a longitudinal design and controlling for social adjustment prior to high school, selection effects cannot be ruled out in interpreting our results. It may be that participants differed in other ways that were not 
captured by controlling for prior levels of social adjustment. As such, our results should be interpreted with caution.

In sum, these findings reinforce the notion that individual trajectories of adjustment best characterize the high school transition, and highlight the role of self-selected contexts in shaping these trajectories. Whereas some adolescents may struggle with the new obstacles afforded by the transition, many others may be able to build on existing resources or take advantage of the opportunities that the move presents. Involvement in organized activities may be one potential avenue for easing transition stress and facilitating social and emotional adjustment across the high school transition. These findings suggest the value of pre-transition planning which encourages adolescents to maintain or initiate involvement in organized activities following the transition to high school as means of facilitating friendships and promoting feelings of well-being.

\section{References}

Asher, S., \& Wheeler, V. (1985). Children's loneliness: A comparison of rejected and neglected peer status. Journal of Consulting and Clinical Psychology, 53, 500-505.

Barber, B. K., \& Olsen, J. A. (2004). Assessing the transitions to middle and high school. Journal of Adolescent Research, 19, 3-30.

Baron, R., \& Kenny, D. (1986). The moderator-mediator variable distinction in social psychological research: Conceptual, strategic, and statistical considerations. Journal of Personality and Social Psychology, 51, 1173-1182.

Berndt, T. J. (1982). The features and effects of friendships in early adolescence. Child Development, 53, 1447-1460.

Berndt, T. J. (1989). Friendships in childhood and adolescence. In. W. Damon (Ed.), Child Development Today and Tomorrow (pp. 332-348). San Francisco, CA: Jossey-Bass.

Berndt, T., Hawkins, J., \& Jian, Z. (1999). Influences of friends and friendships on adjustment to junior high school. Merrill-Palmer Quarterly, 45, 13-41.

Bohnert, A. M., Aikins, J. W., \& Edidin, J. (2007). The role of organized activities in facilitating social adaptation across the transition to college. Journal of Adolescent Research, 22, 1-20.

Bohnert, A., Fredricks, J., \& Randall, E. (2010). Capturing unique dimensions of youth organized activity involvement: Theoretical and methodological considerations. Review of Educational Research, 80, 576-610.

Broh, B. (2002). Linking extracurricular programming to academic achievement: Who benefits and why? Sociology of Education, 75, 69-95.

Bronfenbrenner, U. (1979). Contexts of child rearing: Problems and prospects. American Psychologist, 34, 844-850.

Bukowski, W. M., \& Newcomb, A. F. (1984). Stability and determinants of sociometric status and friendship choice: A longitudinal perspective. Developmental Psychology, 20, 941-952.

Busseri, M. A., Rose-Krasnor, L., Pancer, S. M., Pratt, M. W., Adams, G. R., \& BirnieLefcovitch, S. (2011). A longitudinal study of breadth and intensity of activity involvement and the transition to university. Journal of Research on Adolescence, 21, 512-518.

Cantin, S., \& Boivin, M. (2004). Change and stability in children's social network and self-perceptions during transition from elementary to junior high school. International Journal of Behavioral Development, 28, 561-570. 
Chung, H., Elias, M., \& Schneider, K. (1998). Patterns of individual adjustment changes during middle school transition. Journal of School Psychology, 36, 83-101.

Cillessen, A., \& Mayeux, L. (2007). Expectations and perceptions at school transitions: The role of peer status and aggression. Journal of School Psychology, 45, 567-586.

Cyranowski, J., Frank, E., Young, E., \& Shear, K. (2000). Adolescent onset of the gender difference in lifetime rates of major depression. Archives of General Psychiatry, 57, 21-27.

Denault, A., \& Poulin, F. (2008). Association between interpersonal relationships in organized leisure activities and youth adjustment. The Journal of Early Adolescence, $28,477-502$.

Dohrenwend, B. P., \& Dohrenwend, B. S. (1974). Social and cultural influences on psychopathology. Annual Review of Psychology, 25, 417-452.

Duda, J. L., \& Ntoumanis, N. (2005). After-school sport for children: Implications of a task-involving motivational climate. In J. L. Mahoney, J. Eccles, \& R. Larson (Eds.), After school activities: Contexts of development (pp. 311-330). Mahwah, NJ: Lawrence Erlbaum Associates.

Dworkin, J. B., Larson, R., \& Hansen, D. (2003). Adolescents' accounts of growth experiences in youth activities. Journal of Youth and Adolescence, 32, 17-26.

Eccles, J. S. (2004). Schools, academic motivation, and stage-environment fit. In R. M. Lerner \& L. Steinberg (Eds.), Handbook of adolescent psychology (2nd ed., pp. 125153). Hoboken, NJ: Wiley.

Eccles, J. S., \& Barber, B. L. (1999). Student council, volunteering, basketball, or marching band: What kind of extracurricular involvement matters? Journal of Adolescent Research, 14, 10-43.

Eccles, J. S., Barber, B. L., Stone, M., \& Hunt, J. (2003). Extracurricular activities and adolescent development. Journal of Social Issues, 59, 865-889.

Eder, D., \& Kinney, D. A. (1995). The effect of middle school extracurricular activities on adolescents' popularity and peer status. Youth \& Society, 26, 298-325.

Ellis, S., Rogoff, B., \& Cromer, C. (1981). Age segregation in children's social interactions. Developmental Psychology, 17, 399-407.

Falbo, T., Lein, L., \& Amador, N. (2001). Parental involvement during the transition to high school. Journal of Adolescent Research, 16, 511-529.

Fauth, R. C., Roth, J. L., \& Brooks-Gunn, J. (2007). Does the neighborhood context alter the link between youth's after-school time activities and developmental outcomes? A multilevel analysis. Developmental Psychology, 43, 760-777.

Fenzel, L., \& Blyth, D. (1986). Individual adjustment to school transitions: An exploration of the role supportive peer relations. Journal of Early Adolescence, 6, 315-329.

Fredricks, J. A., \& Eccles, J. S. (2005). Developmental benefits of extracurricular involvement: Do peer characteristics mediate the link between activities and youth outcomes. Journal of Youth and Adolescence, 34, 507-520.

Fredricks, J. A., \& Eccles, J. S. (2006). Is extracurricular participation associated with beneficial outcomes? Concurrent and longitudinal relations. Developmental Psychology, 42, 698-713.

Fredricks, J. A., \& Eccles, J. S. (2008). Participation in extracurricular activities in the middle school years: Are there developmental benefits for African American and European American youth? Journal of Youth Adolescence, 37, 1029-1043.

Goodwin, N. P., Mrug, S., Borch, C., \& Cillessen, A. H. N. (2012). Peer selection and socialization in adolescent depression: The role of school transitions. Journal of Youth and Adolescence, 41, 320-332.

Hansen, D. M., Larson, R. W., \& Dworkin, J. B. (2003). What adolescents learn in organized youth activities: A survey of self-reported developmental experiences. Journal of Research on Adolescence, 13, 25-55. 
Hardy, C. L., Bukowski, W. M., \& Sippola, L. K. (2002). Stability and change in peer relationships during the transition to middle-level school. Journal of Early Adolescence, 22, 117-142.

Hayes, A. F. (2009). Beyond Baron and Kenny: Statistical mediation in the new millennium. Communication Monographs, 76, 408-420.

Hirsch, B. J., \& Dubois, D. L. (1992). The relation of peer social support and psychological symptomatology during the transition to junior high school: A two-year longitudinal analysis. American Journal of Community Psychology, 20, 333-347.

Holmbeck, G. N. (2002). Post-hoc probing of significant moderational and mediational effects in studies of pediatric populations. Journal of Pediatric Psychology, 27, 87-96.

Kovacs, M. (1992). Children's Depression Inventory (CDI). New York, NY: Multi-Health Systems, Inc.

Mahoney, J. L., Cairns, B. D., \& Farmer, T. W. (2003). Promoting interpersonal competence and educational success through extracurricular activity participation. Journal of Educational Psychology, 95, 409-418.

McPherson, M., Smith-Lovin, L., \& Cook, J. M. (2001). Birds of a feather: Homophily in social networks. Annual Review of Sociology, 27, 425-444.

O'Brien, S. F., \& Bierman, K. L. (1988). Conceptions and perceived influence of peer groups: Interviews with preadolescents and adolescents. Child Development, 59, 1360-1365.

Parker, J. G., \& Asher, S. R. (1987). Peer acceptance and later personal adjustment: Are low-accepted children "at risk"? Psychological Bulletin, 102, 357-389.

Patrick, H., Ryan, A., Alfeld-Liro, C., Fredricks, J., Hruda, L., \& Eccles, J. (1999). Adolescents' commitment to developing talent: The role of peers in continuing motivation for sports and the arts. Journal of Youth and Adolescence, 28, 741-763.

Randall, E., \& Bohnert, A. (2009). Organized activity involvement, depressive symptoms, and social adjustment in adolescents: Ethnicity and socioeconomic status as moderators. Journal of Youth and Adolescence, 38, 1187-1198.

Randall, E., \& Bohnert, A. (2011). Understanding threshold effects of organized activity involvement in adolescents: Sex and family income as moderators. Journal of Adolescence, 35, 107-118.

Schaefer, D., Simpkins, S., Vest, A., \& Price, C. (2011). The contribution of extracurricular activities to adolescent friendships: New insights through social network analysis. Developmental Psychology, 47, 1141-1152.

Schulenberg, J. E., Sameroff, A. J., \& Cicchetti, D. (2004). The transition to adulthood as a critical juncture in the course of psychopathology and mental health. Development and Psychopathology, 16, 799-806.

Simpkins, S. D., Eccles, J. S., \& Becnel, J. N. (2008). The mediational role of adolescents' friends in relations between activity breadth and adjustment. Developmental Psychology, 44(4), 1081-1094.

Wargo Aikins, J., Bierman, K. L., \& Parker, J. G. (2005). Navigating the transition to junior high school: The influence of pre-transition friendship and self-system characteristics. Social Development, 14, 42-60.

Weiss, M. R., \& Frazer, K. M. (1995). Initial, continued, and sustained motivation in adolescent female athletes: A season-long analysis. Pediatric Exercise Science, 7, 314-329.

Wigfield, A., Eccles, J. S., Mac Iver, D., Reuman, D. A., \& Midgley, C. (1991). Transitions during early adolescence: Changes in children's domain-specific self-perceptions and general self-esteem across the transition to junior high school. Developmental Psychology, 27, 525-565.

Zimmer-Gemback, M., \& Kindermann, T. (2010). Capturing the peer context: Developmental issues, statistical methods, and new directions. Journal of Adolescence, 33, 783-786. 
AMY M. BOHNERT is an associate professor in the department of psychology at Loyola University Chicago, and can be reached via e-mail at abohner@luc .edu.

JUlie Wargo Aikins is an associate professor at the Department of Psychiatry and Behavioral Neuroscience and Merrill Palmer Skillman Institute, Wayne State University, and can be reached via e-mail at julie.wargo.aikins@wayne .edu.

NiCOLE T. AROLA is a doctoral student in the department of psychology at Loyola University Chicago, and can be reached via e-mail at narola@luc.edu. 